\title{
Lumen-apposing metal stent creating jejuno-jejunostomy for blind pouch syndrome in patients with esophago-jejunostomy after gastrectomy: a novel technique
}

Blind pouch syndrome is characterized by a vicious circle of incomplete pouch clearance and subsequent dilation of the jejunal blind pouch segment in patients with esophago-jejunostomy after total gastrectomy. It manifests as regurgitation, diarrhea, and weight loss. As patients mostly present in a weak general condition and poor nutritional state, surgical revision $[1,2]$ is not always possible.

Between 6/2016 and12/2018, we endoscopically applied lumen-apposing metal stents (LAMS) under endoscopic ultrasound (EUS) guidance to create a jejunojejunostomy in four patients in order to achieve permanent clearance of the blind pouch as well as control of symptoms. Pouch clearance and symptom resolution occurred in all patients within 6 weeks after stent application. The technical approach is illustrated in $\mathbf{F i g .} \mathbf{1}$.

The longest follow-up is 2.5 years. Even long-term stent placement did not show stent-associated bleeding, chronic anemia or stent migration. As far as we know, there are no data describing the experience of long-term LAMS application. Nevertheless, we consider stent replacement after 3 years to prevent late events.

Rinsing and cleaning of the esophagus and the blind pouch was followed by positioning of a naso-enteric tube into the efferent jejunum in order to fill it with saline and to facilitate the identification of the target. The therapeutic echoendoscope (GF-UCT180; Olympus, Tokyo, Japan) was then advanced to the bottom of the blind pouch. An LAMS with ceramic tip and embedded monopolar cutting wire (Hot Axios, $15 \mathrm{~mm}$ diameter, $10 \mathrm{~mm}$ saddle length; Boston Scientific, Marlborough, Massachusetts, USA) was placed through the bottom of the blind pouch into the efferent jejunum, using pure cutting current (dry cut, 100 watts, effect 4; Erbe Elektromedizin $\mathrm{GmbH}$, Tübingen, Germany). When the device reached the efferent jejunum, the distal flange of the

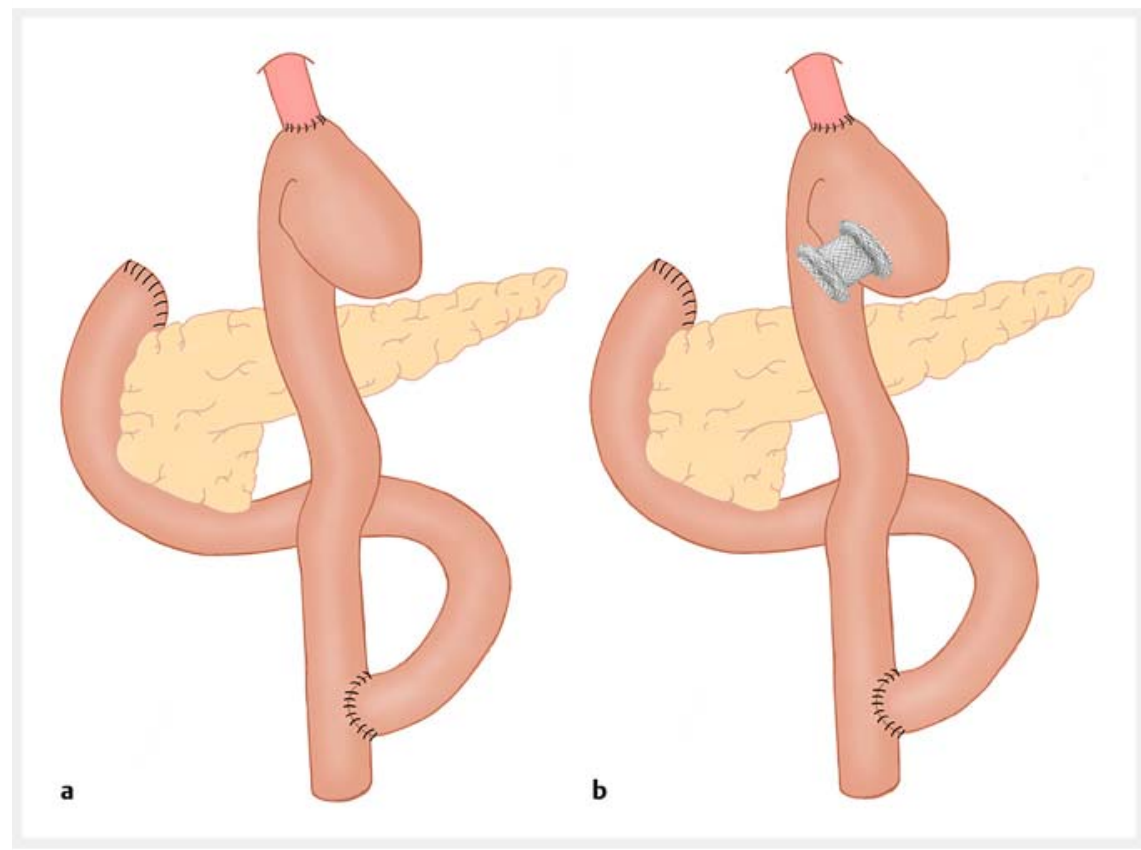

- Fig. 1 Technical approach. a Esophago-jejunostomy after total gastrectomy. b Position of the lumen-apposing metal stent to create a jejuno-jejunostomy. Source: Magdalena Wundsam

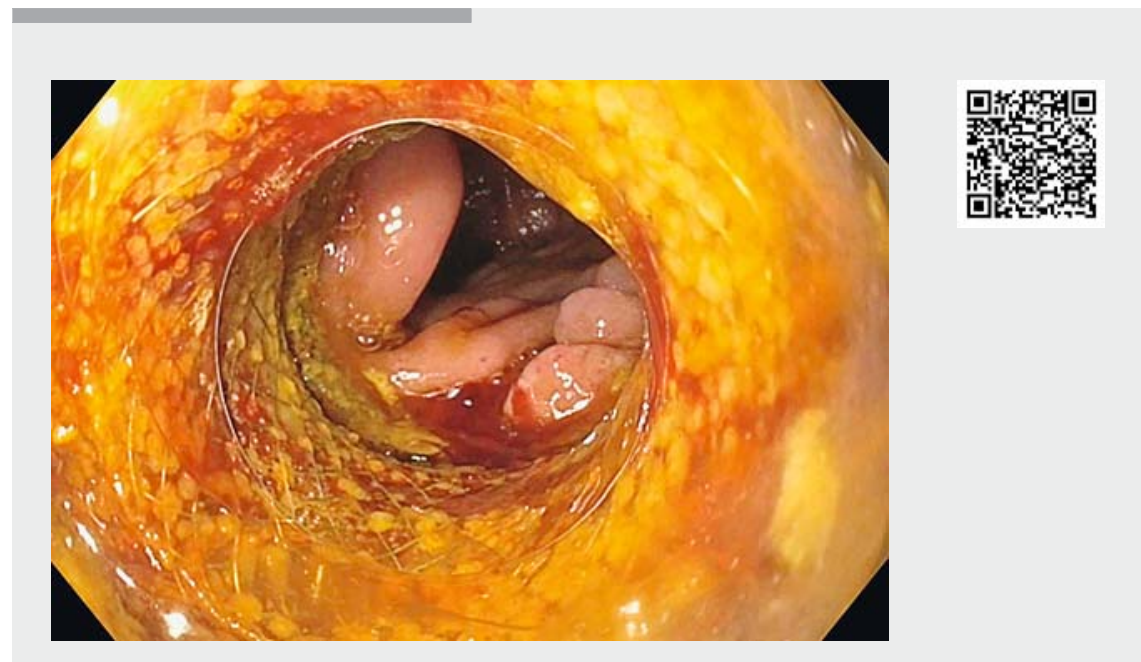

$\checkmark$ Video 1 Lumen-apposing metal stent creating jejuno-jejunostomy for blind pouch syndrome in patients with esophago-jejunostomy after gastrectomy.

stent was deployed and the device was safely anchored into the target organ. The proximal flange was then opened and the lumen apposition between the blind pouch and the efferent jejunum was complete ( $\triangleright$ Video 1 ).

Endoscopy_UCTN_Code_TTT_1AS_2AG 


\section{Acknowledgment}

We kindly acknowledge the artwork of Magdalena Wundsam ( $\triangleright$ Fig. 1 ) and video editing of Markus Acko, MD, and Richard Pfandner, MD.

Competing interests

None

The authors

Helwig V. Wundsam ${ }^{1}$, Viktoria Kertesz ${ }^{2}$, Franziska Bräuer ${ }^{1}$, Ines Fischer ${ }^{1}$, Johannes Zacherl $^{2}$, Reinhold Függer ${ }^{1}$, Georg O. Spaun ${ }^{1}$

1 Department of General and Visceral Surgery, Congregation Hospital (Sisters of Charity), Linz, Austria

2 Surgical Department, St. Josef Hospital Vienna, Vienna, Austria

\section{Corresponding author}

\section{Helwig Wundsam, MD}

Department of General and Visceral Surgery, Congregation Hospital (Sisters of Charity), Seilerstätte 4, 4020 Linz, Austria

Fax: +43-732-7677-7200

helwig.wundsam@ordensklinikum.at

\section{References}

[1] Takiguchi S, Yano H, Sekimoto M et al. Laparoscopic surgery for blind pouch syndrome following Roux-en Y gastrojejunostomy: report of a case. Surg Today 1999; 29 : $553-556$

[2] Vettoretto N, Poiatti R, Ghilardi G et al. Blind pouch syndrome secondary to gastrojejunostomy. Report of a case. Chir Ital 2006; 58: $263-266$

\section{Bibliography}

DOI https://doi.org/10.1055/a-0985-4023

Published online: 21.8.2019

Endoscopy 2020; 52: E35-E36

(c) Georg Thieme Verlag KG

Stuttgart · New York

ISSN 0013-726X

\section{ENDOSCOPY E-VIDEOS \\ https:/|eref.thieme.de/e-videos}

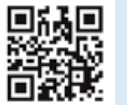

Endoscopy E-Videos is a free access online section, reporting on interesting cases and new techniques in gastroenterological endoscopy. All papers include a high quality video and all contributions are freely accessible online.

This section has its own submission website at

https://mc.manuscriptcentral.com/e-videos 